\title{
Omega-3 Uzun Zincirli Çoklu Doymamış Yağ Asitleri ve Fenilketonüri
}

\author{
Omega-3 Long-Chain Polyunsaturated Fatty Acids and Phenylketonuria
}

\author{
Zeynep Caferoğlư1, Hülya Gökmen Özel ${ }^{2}$
}

Geliş tarihi/Received: 18.08.2017 • Kabul tarihi/Accepted: 20.11.2018

\section{ÖZET}

Beyin, retina ve diğer sinir dokuları uzun zincirli çoklu doymamış yağ asitlerinden (UZÇDYA) zengindir. Birçok klinik ve epidemiyolojik çalışma ile omega-3 UZÇDYA'ların çocukluk çağındaki nöral gelişim üzerine olumlu etkileri olduğu kanitlanmıştır. Uzun zincirli ÇDYA'lar, diyetle alımları yeterli olduğu sürece temel elzem yağ asitlerinden endojen olarak sentezlenebilirler. Aynı zamanda, et, balık, yumurta, karaciğer ve süt ürünleri gibi proteinden zengin besinler eikosapentaenoik asit (EPA) ve dokosaheksaenoik asit (DHA) gibi UZÇDYA'ların en belirgin diyetsel kaynaklarıdır. Bununla birlikte, klasik fenilketonürili (FKÜ) hastalar yüksek plazma fenilalanin düzeyleri ve nörolojik hasarı önlemek için diyet protein alımında sıkı ve ömür boyu süren bir sınırlamaya gereksinme duyarlar. Bu katı metabolik kontrol sadece düşük miktarda vitamin ve mineral sağlamakla kalmaz, genellikle doymuş yağ asitleri ve çDYA'ların da düşük miktarda alınmasına neden olur. Bu nedenle, FKÜ’lü hastaların sağlıklı kontrollerle karşılaştırıldığında UZÇDYA alımları daha az olmakta ve daha düşük plazma ve eritrosit UZÇDYA düzeylerine sahip olmaktadırlar. Bebeklik ve çocukluk döneminde, UZÇDYA'lar normal nörogelişim için önemlidir. Yetersizliği, okul öncesi ve okul çağındaki FKÜ’lü çocuklarda erken dönemde saptanabilen merkezi sinir sistemi işlev bozukluklarına katkıda bulunabilir. Ayrıca, UZÇDYA yetersizliğinin kronik nörolojik, inflamatuvar ve metabolik bozukluklara neden olabileceği de ileri sürülmektedir. Diğer taraftan, randomize kontrollü çalışmalardan elde edilen veriler, FKÜ’lü hastalardaki UZÇDYA durumunun diyet desteği ile iyileştirilebileceğini önermektedir. Bu derleme yazıda, fenilalaninden kısıtlı diyetler ile UZÇDYA arasındaki ilişki incelenmiş ve FKÜ’ü hastalar için UZÇDYA’ların önemi ele alınmıştır.

Anahtar kelimeler: Omega-3, uzun zincirli çoklu doymamış yağ asitleri, fenilketonüri, diyet

\section{ABSTRACT}

The brain, retina and other nervous tissues are rich in long chain polyunsaturated fatty acids (LCPUFA). Many clinical and epidemiological studies have proven omega-3 LCPUFA to produce positive effects on neural development in childhood. Long-chain PUFA can be synthesised endogenously from the parent essential fatty acids when dietary intakes are adequate. Protein-rich foods such as meat, fish, eggs, liver and milk products are also the predominant dietary sources of LCPUFA, such as eicosapentaenoic acid (EPA) and docosahexaenoic acid (DHA). However, patients with classical phenylketonuria (PKU) require strict lifelong limitation of dietary protein intake to avoid high plasma concentrations of phenylalanine and neurological damage. This type of strict metabolic control usually provides not only lower amounts of vitamins and minerals but also lower amounts of saturated fatty acids and PUFA. Therefore, PKU patients have very low LCPUFA intakes and reduced LCPUFA concentrations in plasma and erythrocytes as compared to healthy controls. During infancy and childhood, LCPUFA are important for normal neurodevelopment. A deficiency may contribute to disturbances in the function of the

1. İletişim/Correspondence: Erciyes Üniversitesi, Sağlık Bilimleri Fakültesi, Beslenme ve Diyetetik Bölümü, Kayseri, Türkiye • E-posta: zeynepcaferoglu@gmail.com (ㄱ) https://orcid.org/0000-0002-7226-5636
2. Hacettepe Üniversitesi, Sağlık Bilimleri Fakültesi, Beslenme ve Diyetetik Bölümü, Ankara, Türkiye (ㄱ) https://orcid.org/0000-0002-8282-6468 
central nervous system, which are detectable as early as in preschool and school-age children with PKU. Moreover, it has been suggested that the LCPUFA deficiency may lead to chronic neurological, inflammatory and metabolic disorders. On the other hand, data from randomized controlled trials suggest that LCPUFA status in patients with PKU may be improved by dietary supplementation. In this review, the association between phenylalanine restricted diets and LCPUFA was investigated and the importance of LCPUFA for patients with PKU was discussed.

Keywords: Omega-3, long chain polyunsaturated fatty acids, phenylketonuria, diet

\section{GİRIŞ}

Yağ tüketiminin yaşamın sürekliliği için elzem olduğu ilk kez 1929 yılında yağsız diyet verilen farelerde büyümede gerilik, hastalık ve ölümlerin gözlendiği çalışma sonucunda bildirilmiştir (1). Omega-3 (n-3) yă̆ asitlerinin önemi ise ilk defa 1970’li yıllarda Grönland eskimoları üzerinde yapılan çalışmalarda fark edilmiştir. Geleneksel besinleri yüksek oranda yağ içermesine rağmen, eskimoların kalp ve romatizmal hastalıklar, astım ve endüstriyel ülkelerde sık görülen pek çok hastalığa karşı dirençli oldukları gözlenmiştir (2). Bunun nedeninin doymamış yağları içeren balık etleri ve deniz memelilerinin yağlarını yaygın olarak tüketmeleri olduğu ileri sürülmüştür (3).

Et, süt ürünleri, yumurta ve balık gibi proteinden zengin besinler özellikle doymuş yağ asitleri ve uzun zincirli çoklu doymamış yağ asitlerinden (UZÇDYA) oluşan hayvansal yağların primer besinsel kaynaklarıdır (4). Ancak UZÇDYA'dan zengin besinler (yağlı balık, yumurta ya da sakatat gibi) yüksek protein içerdikleri için fenilketonürili (FKÜ) çocukların diyetinden çıkarılır (5). Bu nedenle, FKÜ’lü hastaların diyetle UZÇDYA alım düzeyleri yetersiz kalmaktadır (4). Bununla birlikte, yeterli UZÇDYA alımının özellikle bebek ve çocuklarda, normal nörogelişim için oldukça önemli olduğu bilinmektedir (6). Yetersizlik, okul öncesi ve okul çağında olan FKÜ’lü çocuklarda merkezi sinir sisteminin işlevlerinde bozulmalara neden olabilmektedir (7). Ayrıca, tedavi edilmeyen FKÜ veya kötü metabolik kontrol, çeşitli davranışsal bozuklukları (psikotik, otistik ve agresif bozukluklar) kapsayan psikiyatrik hastalıkların eşlik ettiği progresif zihinsel gerilikle ilişkilidir (8). $\mathrm{Bu}$ sorunların çözümünde de UZÇDYA'ların yararlı olabileceği düşünülmektedir. Bu derleme yazıda, fenilalaninden kısıtlı diyetler ile UZÇDYA arasındaki ilişki incelenmiş ve FKÜ’lü hastalar için UZÇDYA’ların önemi ele alınmıştır.

\section{Uzun Zincirli Çoklu Doymamış Yağ Asitleri}

Vücudun üretemediği ve mutlaka besinler yoluyla alınması gereken yağ asitlerine elzem yağ asitleri (EYA) ismi verilmektedir. Vücutta n-3 ve n-6 olmak üzere iki tip EYA bulunur. Omega-3 serisi 18 karbonlu ve üç çift bağ içeren $a$-linolenik asitten (ALA, 18:3), n-6 serisi ise 18 karbonlu ve iki çift bağ içeren linoleik asitten (LA, 18:2) oluşur (9). Alfa-linolenik asitten sentezlenen eikosapentaenoik asit (EPA, 20:5, n-3) ve dokosaheksaenoik asit (DHA, 22:6, n-3) büyüme ve normal hücresel işlevler için elzem besin ögeleridir. Dokosaheksaenoik asit, özellikle sinir dokusu ve retinadaki fosfolipitlerin bileşenidir ve santral sinir sisteminin normal yapı ve işlevlerinin devamlılığı ve gelişimi için gereklidir (10,11). Araşidonikasit(AA, 20:4, n-6) ve DHA, beyinde gri maddenin kuru ağırlığının \%6'sını oluşturmaktadır. Beyin yapısı ve işlevlerine esas etkileri ise nöron membranlarının akışkanlığını sağlaması, beyinin nörotransmitterlerinin sentezi ve fizyolojik işlevlerinde rol almasıdır (11). Ayrıca, UZÇDYA'ların kognitif gelişimde oldukça önemli bir role sahip olduklarına ilişkin kanıtlar giderek artmaktadır. Hem DHA hem de AA, bilişsel işlevler için önemlidir. Bu işlevler hafıza, öğrenme, muhakeme, dikkat ve konuşmayı kapsamaktadır (12).

Omega-3 ve omega-6 yağ asitleri doğum öncesi ve sonrasında beyinde hızla birikir. En hızlı birikim intrauterin yaşamda (gebeliğin 3. trimesteri) ve postnatal yaşamın 12. haftasına kadar olan dönemde gerçekleşmektedir. Anne sütü lipitlerinde 
bu yağ asitleri yeterli düzeyde bulunmaktadır. $\mathrm{Bu}$ yağ asitlerinin aynı zamanda bebek besinleri ve mamalarda, enteral ve parenteral çözeltilerde yeterli düzeyde bulundurulması önerilmektedir (11). Dünyanın farklı birçok bölgesinde yapılmış toplam 65 çalışmanın analizinde, anne sütündeki DHA miktarı toplam yağ asidinin \%0.32'si ve AA miktarı \%0.47'si olarak bulunmuştur (13). Anne sütünün EPA değerlerine dair ise global bir ortalama miktar bulunmamakla birlikte 9 farklı ülkenin verilerini değerlendiren bir analizde, toplam yağ asidinin \%0.07-0.26 aralığında değiştiği görülmüştür (14). Bu verilere göre anne sütü yaklaşık 13 mg DHA ve $4.5 \mathrm{mg}$ EPA içermektedir. Anne sütü, inek sütü, mamalar ve aminoasit karışımlarının EYA ve UZÇDYA bileşimleri Tablo 1 ve 2'de verilmiştir.

Tablo 1. Anne sütü ve inek sütünün elzem yağ asidi bileşimi (g/100 mL)

\begin{tabular}{lcc}
\hline Yağ asidi & Anne sütü & İnek sütü \\
\hline Omega-6 serisi & & \\
Linoleik asit & 8.3 & 1.1 \\
Araşidonik asit & 1.8 & 1.0 \\
Toplam & 10.1 & 2.1 \\
Omega-3 serisi & & \\
a-linolenik asit & 0.4 & Yok \\
Eikosapentaenoik asit & Var & Yok \\
Dokosaheksaenoik asit & Var & Yok \\
\hline
\end{tabular}

Birçok ulusal ve uluslararası organizasyonun rehberlerinde, bebek ve yetişkinlerde UZÇDYA için diyetle DHA ve EPA alım düzeyi önerilerine yer verilmiştir. Yetişkinler için bu öneriler, temel olarak kardiyovasküler hastalıklardan primer ve sekonder korunma amaçlıdır ve günlük 90-1000 mg EPA+DHA aralığında değişmektedir (10,15-19). Gebe ve emziren kadınlar için önerilen günlük alım en az 200 mg DHA içerecek düzeydedir ve bu gereksinme fetüs ve bebeğin gelişiminde olası yararlı etkileri temel alınarak belirlenmiştir (20). Bebekler için (0-2 yaş) 1994 yılında Dünya Sağlık Örgütü, büyüme ve gelişme için günlük 20 mg/kg DHA alımını önermiştir $(15,16)$. İki yaşından büyük çocuklar için ise diyetle alınması gereken EPA ve/veya DHA miktarına ilişkin görüş birliği olmamakla birlikte, yetişkin toplum için (haftada 1-2 porsiyon yağlı balık veya yaklaşık 250 mg/gün EPA ve DHA) olan öneriler benimsenmektedir (21,22).

\section{Uzun Zincirli Çoklu Doymamış Yağ Asitleri ve Fenilketonüri}

Fenilalanin kısıtlı diyet alan FKÜ'lü hastaların potansiyel olarak diyetle yetersiz UZÇDYA alımları son zamanlarda üzerinde çalışllan bir konudur. İnsan organizmasında UZÇDYA'ların 2 temel kaynağı vardır. Bunlar diyetle alım ve elzem metabolitler olan LA ve ALA'dan endojen sentezdir (5). Bununla birlikte, AA ve DHA'nın endojen sentezi sinırlıdır (23), bu nedenle UZÇDYA öncüllerinin diyette eksikliği yetersizliklere yol açabilir. Ayrıca, FKÜ’de fenilalanin metabolitlerinin endojen DHA sentezi üzerine baskılayıcı etkileri olduğu düşünülmektedir (24).

Fenilketonürili çocukların diyet yağ bileşimini ve plazma veya eritrosit UZÇDYA düzeylerini belirlemek amacıyla çeşitli çalışmalar yapılmıştır (5,25-28). Cornejo ve arkadaşları (25), tarafından yapılan çalışmada, fenilalanin kısıtlı diyet alan 29 FKÜ’lü çocuğun toplam enerji alımlarının \%31.8'inin yağdan sağlandığı ve bunun \%13'ünü LA, \%0.2'sini ise ALA'nın oluşturduğu bulunmuştur. Doymuş/tekli doymamış/ çoklu doymamış yağ asidi oranı 1/1.7/3.9 ve LA/ALA oranı önerilenden on kat daha fazla (115/1) olarak hesaplanmış ve fenilalanin kısıtlı diyetin yüksek LA ve düşük ALA içerdiği sonucuna ulaşılmıştır (25). Başka bir çalışmada ise FKÜ'lü çocukların, sağlıklı çocuklara göre anlamlı olarak daha yüksek ÇDYA tükettikleri, ancak toplam eritrosit lipitlerindeki toplam n-3, n-6, doymuş ve ÇDYA düzeylerinin sağlıklı çocuklardan daha düşük olduğu saptanmıştır (26).

Hiperfenilalaninemili çocuklar ile yapılan çalışmada da benzer sonuçlar elde edilmiştir. Normal diyet alan hiperfenilalaninemili çocukların plazma fosfolipit UZÇDYA düzeyleri FKÜ'lü çocuklardan farklı değilken, sağlıklı çocuklara göre daha düşük olduğu saptanmıştır (27). Dokuz vaka-kontrol çalışmasının dahil edildiği bir meta-analizde ise FKÜ'lü hastaların incelenen tüm plazma ve eritrosit göstergelerinde EPA 
Tablo 2. Mamalarda ve aminoasit karışımlarında bulunan elzem yağ asidi miktarları (100 mL)

\begin{tabular}{|c|c|c|c|}
\hline Ürün adı & LA (mg) & ALA (mg) & UZÇDYA \\
\hline \multicolumn{4}{|l|}{ Bebek ve devam mamaları } \\
\hline Aptamil 1 & 459 & 85 & $12 \mathrm{mg}$ AA + $11 \mathrm{mg}$ DHA \\
\hline Aptamil 2 & 400 & 74 & $8.6 \mathrm{mg} \mathrm{AA}+8.6 \mathrm{mg} \mathrm{DHA}$ \\
\hline Aptamil 3 & 410 & 76 & $8.6 \mathrm{mg} \mathrm{AA}+8.6 \mathrm{mg}$ DHA \\
\hline Aptamil 4 & 383 & 68 & UZÇDYA içerir \\
\hline Aptamil 5 & 354 & 62 & UZÇDYA içerir \\
\hline Bebelac 1 & NS & NS & NS \\
\hline Bebelac 2 & NS & NS & NS \\
\hline Bebelac 3 & NS & NS & NS \\
\hline Bebelac 4 & NS & NS & NS \\
\hline Bebelac Gold 1 & NS & NS & EYA içerir \\
\hline Bebelac Gold 2 & NS & NS & EYA içerir \\
\hline Bebelac Gold 3 & NS & NS & EYA içerir \\
\hline Bebelac Gold 4 & NS & NS & EYA içerir \\
\hline Bebelac Gold 5 & NS & NS & EYA içerir \\
\hline SMA 1 & 520 & 42 & $12 \mathrm{mg}$ AA + $7.1 \mathrm{mg}$ DHA \\
\hline SMA 2 & NS & NS & NS \\
\hline SMA 3 & 520 & 48 & $12 \mathrm{mg}$ AA + $7.1 \mathrm{mg}$ DHA \\
\hline Similac 1 & 570 & 60 & $15 \mathrm{mg}$ AA + 9 mg DHA \\
\hline Similac 2 & 630 & 60 & $11 \mathrm{mg}$ AA + 9 mg DHA \\
\hline Similac 3 & 610 & 50 & 10 mg AA + 8 mg DHA \\
\hline Hero 1 & NS & NS & NS \\
\hline Hero 2 & 429 & 51.5 & NS \\
\hline Hero 3 & NS & NS & NS \\
\hline Evolvia NutriPRO 1 & 569 & 49 & $15.8 \mathrm{mg}$ AA + $11.2 \mathrm{mg}$ DHA \\
\hline Evolvia NutriPRO 2 & 517 & 45 & $10.2 \mathrm{mg} \mathrm{AA}+10.2 \mathrm{mg} \mathrm{DHA}$ \\
\hline Evolvia NutriPRO 3 & 517 & 42 & $0.6 \mathrm{mg} \mathrm{AA}+0.3 \mathrm{mg} \mathrm{DHA}$ \\
\hline Humana 1 & 598 & 65 & NS \\
\hline Humana 2 & 612 & 86 & NS \\
\hline Humana 3 & 559 & 79 & NS \\
\hline Hipp 1 organik & 600 & 70 & 20 mg UZÇDYA \\
\hline Hipp 2 organik & 700 & 70 & NS \\
\hline Hipp 3 organik & 700 & 70 & NS \\
\hline \multicolumn{4}{|l|}{ Aminoasit karışımları } \\
\hline PKU Anamix infant (100 g) & 4100 & 660 & 140 mg AA + 70 mg DHA \\
\hline PKU 1 & - & - & - \\
\hline PKU 2 prima & - & - & - \\
\hline PKU 2 secunda & - & - & - \\
\hline PKU 3 & - & - & - \\
\hline PKU Lophlex LQ (125 mL) & - & - & 150 mg DHA \\
\hline PKU Cooler10 (87 mL) & NS & NS & 67 mg DHA + 15 mg EPA \\
\hline PKU Cooler15 (130 mL) & NS & NS & $100 \mathrm{mg}$ DHA + 23 mg EPA \\
\hline PKU express & NS & NS & NS \\
\hline Comida PKU A formula & 450 & 70 & NS \\
\hline Comida PKU A & NS & NS & NS \\
\hline Comida PKU B & NS & NS & NS \\
\hline Comida PKU C & NS & NS & NS \\
\hline Comida PKU C kapsül & NS & NS & NS \\
\hline
\end{tabular}


ve DHA düzeylerinin sağlıklı çocuklardan daha düşük olduğu, ancak AA'nın sadece plazma total lipitlerinde önemli düzeyde düşük olduğu bulunmuştur (5). Diğer taraftan, Gramer ve arkadaşları (28) tarafından 2016 yılında yayınlanan makalede, FKÜ’lü çocukların plazma ve eritrosit EPA ve DHA düzeylerinin sağlıklı kontrollerden farklı olmadığı gösterilmiştir. Bununla birlikte, FKÜ'lü hastaların fenilalanin düzeyleri ile eritrosit DHA düzeyleri arasında negatif korelasyon saptanmış olması, iyi diyet kontrolünün daha yüksek UZÇDYA düzeyleriyle ilişkili olabileceğine işaret etmektedir (28).

\section{Fenilketonüride Aterosklerotik Değişiklikler ve Uzun Zincirli Çoklu Doymamış Yağ Asitleri}

Uzun zincirli ÇDYA'lardan AA, DHA ve EPA'nın sağlık ve hastalıktaki inflamatuvar ve hemostazolojik süreçlere etkisi tartışmalıdır (29,30). Eikosanoidlerin öncüsü olan AA, proinflamatuvar yanıt ve hemostazda merkezi bir rol oynamaktadır (29). Fenilketonürili hastalarda azalmış UZÇDYA alımının hemostazolojik süreçleri etkileyebileceğine dair bazı kanıtlar vardır ve serumda AA düzeylerinin azaldığı bulunmuştur (31). Yapılan bir çalışmada, iyi metabolik kontrollü FKÜ hastalarında uzun dönem diyetle kısıtlı yağ asidi alımının mitokondriyal §-oksidasyon yolağını ve enerji metabolizmasını etkilediği, ancak kolesterol metabolizması ve platelet agregasyonu üzerine işlevsel etkilerinin olmadığı sonucuna varılmıştır (32). Htun ve arkadaşları (33) tarafından 2015 yılında yapılan çalışmada ise FKÜ’lü hastaların sağlıklı gruba göre HDL kolesterol düzeyleri daha düşük ve trigliserit düzeyleri daha yüksek bulunurken, n-6 ya da n-3 yağ asidiprofilleriarasında önemli bir farkbulunmamıştır. Gruplar arasında karotis intima-media kalınlığl, §̧-sertlik indeksi ve platelet aktivasyonu düzeylerinin de benzer olduğu saptanmıştır. Bu sonuçlar, balık içermeyen FKÜ diyetinin erken aterosklerotik değişikliklere ve platelet aktivasyonuna neden olmadığını göstermektedir. Fenilketonürili hastaların n-3 yağ asitlerinden zengin bitkisel yağların tüketimi ile diyetteki balık eksikliğini kompanse ettikleri ve bu sayede n-3 yağ asidi düzeylerinin sağlıklı kontrollerden farklı çıkmadığı düşünülmektedir. Bununla birlikte, FKÜ'lü hastalarda n-3 desteğinin aterosklerotik göstergeler ve platelet işlevleri üzerine uzun dönem etkileri henüz bilinmemektedir (33).

\section{Fenilketonüride Nörokognitif Gelişim ve Uzun Zincirli Çoklu Doymamış Yağ Asitleri}

FKÜ’lü hastalarda görülen artmış plazma fenilalanin düzeyleri ile nörolojik bozukluklar arasındaki ilişki tam olarak tanımlanmıştır (34). Erken ve iyi tedavi edilen FKÜ’lü hastalarda bile işlevsel eksiklikler olabilmektedir. Fenilketonürili hastalar sağlıklı kontrollerle karşılaştırıldığında daha düşük zeka puanlarına sahiptir (35). Fenilketonüride planlama, problem çözme, bilgiyi yorumlama ve dikkatini toplama gibi yönetimsel yeteneklerde bozulmaları kapsayan hemen göze çarpmayan anomaliler görülmektedir (36). Ayrıca, FKÜ'lü çocuklar davranışsal anomaliler, motor disfonksiyonu ve bozulmuş hafızaya sahip olmaktadır (37). Bu verilere dayanılarak, FKÜ’lü hastalarda gözlenen nörolojik anomalilerin UZÇDYA yetersizliğinden, özellikle yetersiz DHA alımından kaynaklanabileceği hipotezi önerilmektedir.

Fenilketonürili hastalarda n-3 UZÇDYA'ların motor davranışlar üzerine etkilerini incelemek amacıyla yapılan bir çalışmada, iyi metabolik kontrollü klasik FKÜ'lü hastaların plazma fosfolipitlerindeki n-3 UZÇDYA düzeylerinin ve motometrik RostockOseretzky Ölçeği (ROÖ) sonuçlarının çalışma başlangıcında sağlıklı kontrollerden daha düşük olduğu, ancak üç aylık $15 \mathrm{mg} / \mathrm{kg}$ DHA desteğinden sonra fosfolipit n-3 UZÇDYA düzeylerinin arttığı, n-6 düzeylerinin azaldığı ve ROÖ performanslarının iyileştiği gösterilmiştir (38). Daha sonraki yıllarda aynı hasta grubunun, Koletzko ve arkadaşları (39) tarafindan görsel uyarılmış potansiyel (GUP) test sonuçları yayınlanmış ve üç aylık desteğin GUP latenslerinde iyileşme sağladığı gösterilmiştir. Ince motor ve koordinasyon becerileri olan GUP latenslerinin iyileşmesi, FKÜ’lü çocuklarda nöral normalite için n-3 UZÇDYA desteğinin gerekli olduğuna işaret etmektedir (39). 
Fenilketonüride Uzun Zincirli Çoklu Doymamış Yağ Asitleri Desteği

Her ne kadar FKÜ'lü hastalarda UZÇDYA düzeylerinin düşük olduğu ve diyetle UZÇDYA desteğinin sonuçlarda iyileşme sağlayabileceği gösterilmiş olsa da yapılacak desteğin en uygun dozu, formu veya süresine ilişkin henüz bir fikir birliği yoktur. Altı randomize kontrollü çalışmanın meta-analizinde (5), farklı yaş gruplarından (bebek, çocuk ve yetişkin) FKÜ'lü hastalara çeşitli süre (4.5 ay-1 yll) ve formlarda (balık yağı, mikroalg yağı, UZÇDYA içeren mama veya EYA eklenmiş aminoasit karışımı) yapılan UZÇDYA desteklerinin (18g EPA ve/veya 0.27-12g DHA ve/ veya $0.46-0.7 \mathrm{~g}$ AA veya $17.2 \mathrm{~g}$ LA ve $4.5 \mathrm{~g}$ ALA/100 g yağ asidi) plazma ve eritrosit DHA düzeylerine etkileri incelenmiş ve tüm n-3 UZÇDYA desteklerinin DHA düzeylerinde artış sağladığı gösterilmiştir (5). Benzer şekilde, hiperfenilalaninemili çocuklarda 12 ay boyunca yapılan UZÇDYA desteğinin (günlük enerji gereksiniminin \%0.3-0.5’i) başlangiçta düşük olan plazma ve eritrosit DHA düzeylerinde yaklaşık \%100 artış sağladığı görülmüştür (40). Aynı hasta grubu 12 aylık destek sonrası üç yıl süreyle izlenmiş ve üç yılın sonunda DHA düzeylerinin başlangıçtaki değerlere döndüğü saptanmıştır (41). Bu veriler, UZÇDYA desteğinin sürekli olmasının önemini vurgulamaktadır.

Ülkemizde yapılan bir çalışmada, zeka geriliği olmayan FKÜ'lü hastaların diyetlerine 6 ay boyunca 500 mg/gün (\%18 EPA, \%12 DHA) balık yağı eklenmiştir (42). Araştırma sonucunda çocukların vücut ağırlığı, boy uzunluğu, beden kütle indeksi ve HDL kolesterol düzeylerinde istatistiksel olarak anlamlı düzeyde artış olurken, total kolesterol, trigliserid, LDL ve VLDL kolesterol düzeylerinde ise azalma rapor edilmiştir. Aynı zamanda, çocukların sözel, performans ve toplam zeka testi puanlarında da önemli düzeyde artış olmuştur (42). Diğer taraftan, yapılan bir çalışmada balık yağı (\%18 EPA, \%12 DHA ve \%22 $\gamma$-linoleik asit) yerine AA eklenmiş desteklerin (1 saşe - 4g, 200 mg AA ve 100 mg DHA) kullanımının FKÜ’lü hastalarda, plazma ve eritrosit DHA düzeyleri ile birlikte AA düzeylerinde de iyileşme sağlayabileceği gösterilmiştir (43).

Fenilketonürili hastalarda n-3 UZÇDYA desteği yapılırken, kullanılan desteğin eğer varsa vitamin içeriği de dikkate alınmalıdır. Özellikle aminoasit karışımı ile birlikte multivitamin desteği alan hastaların diyetine n-3 UZÇDYA desteği eklenmesiyle, günlük toplam vitamin alımları önerilen miktarların üzerine çıkabilmektedir. Örneğin 7 yaşında klasik FKÜ'lü bir çocuğun 40 g protein gereksinmesinin (44) doğal besinlerden (400 mg fenilalanin ve yaklaşık 8 g protein) aldığı miktar dışında kalan kısmını karşılamak için tükettiği günlük $53 \mathrm{~g}$ aminoasit karışımına (PKU 2 prima) ek olarak önerilen dozlarda multivitamin (5 mL Supravit) ve balık yağı desteği (5 mL Möller’s omega-3) kullandığı düşünüldüğünde günlük toplam vitamin alım miktarları Tablo 3’teki gibidir. Günlük alınacak n-3 UZÇDYA miktarı (400 mg EPA + 600 mg DHA), sağlık otoriteleri tarafindan diyetle alınması önerilen miktarları (900-1000 mg EPA+DHA) karşılarken, vitamin alım düzeyleri gereksinimin oldukça üzerine çıkmaktadır. Çocuklarda günlük vitamin alımının, önerilen düzeylerin üzerinde olması büyüme-gelişme, bağışılklk sistemi ve metabolik süreçleri olumsuz yönde etkileyebileceği gibi özellikle yağda eriyen vitaminler (A, D, E gibi) vücutta depo edildikleri için toksik etki göstererek çeşitli sağlık sorunlarına neden olabilmektedir.

\section{SONUÇ VE ÖNERİLER}

Yapılan gözlemsel çalışmalar sonucunda geleneksel FKÜ diyeti ile UZÇDYA'ların yetersiz alımının özellikle FKÜ'lü bebeklerde sağlıklı bebeklere göre daha düşük plazma ve eritrosit n-3 UZÇDYA, özellikle DHA düzeylerine neden olduğu gösterilmiştir. Ayrıca, diyetle alınan prekürsörlerinden endojen UZÇDYA sentezinin de yetersiz UZÇDYA alımını kompanse etmek için yeterli olmadığı bilinmektedir. $\mathrm{Bu}$ nedenle, olası n-3 UZÇDYA yetersizliğinin yol açabileceği olumsuz sonuçları önlemek amacıyla FKÜ’lü bebek ve çocuklara yapılacak n-3 UZÇDYA desteğinin plazma ve eritrosit düzeylerinde artış ile sonuçlanacağı ve bu sayede nöral işlevleri 
Tablo 3. Günlük aminoasit karışımı, multivitamin ve balık yağı desteği ile alınan vitamin miktarları ve gereksinmeyi karşılama düzeyleri

\begin{tabular}{lcccccc}
\hline Vitaminler & $\begin{array}{c}\text { PKU 2 prima } \\
\mathbf{5 3} \mathbf{~ g})\end{array}$ & $\begin{array}{c}\text { Supravit } \\
\mathbf{( 5 ~} \mathbf{~} \mathbf{)}\end{array}$ & $\begin{array}{c}\text { Möller's omega-3 } \\
\mathbf{( 5 ~} \mathbf{~} \mathbf{)}\end{array}$ & Toplam & Gereksinme* & Karşılanma \%'si \\
\hline A (IU) & 2099 & 2500 & 915 & 5514 & 1667 & 331 \\
D (IU) & 382 & 400 & 400 & 1182 & 400 & 296 \\
E (mg) & 11 & 9 & 10 & 30 & 7 & 429 \\
C (mg) & 95 & 45 & - & 140 & 60 & 233 \\
$\mathrm{~B}_{6}(\mathrm{mg})$ & 1.43 & 1.3 & - & 2.73 & 0.6 & 455 \\
$\mathrm{~B}_{1}(\mathrm{mg})$ & 0.95 & 0.9 & - & 1.85 & 0.6 & 308 \\
$\mathrm{~B}_{2}(\mathrm{mg})$ & 1.27 & 1 & - & 2.27 & 0.6 & 378 \\
$\mathrm{~B}_{3}(\mathrm{mg})$ & 6.68 & 11 & - & 17.68 & 8 & 221 \\
\hline
\end{tabular}

*Besin ögesi gereksinimleri Türkiye’ye Özgü Besin ve Beslenme Rehberi (2015)'ne göre değerlendirilmiştir.

iyileştirerek, kognitif bozuklukların gelişmesini önleyerek ya da işlevsel kayıpların meydana gelmesine engel olarak uzun dönemde yararlı etkiler sağlayabileceği önerilmektedir. Bununla birlikte, FKÜ diyetine yapılacak n-3 UZÇDYA desteğinin görsel, kognitif ve diğer işlevler üzerine kısa ve uzun dönem olası olumlu veya olumsuz sonuçlarına ilişkin kanıt sağlayacak daha fazla çalışmaya gereksinme vardır.

Fenilketonürili hastalarda n-3 yağ asidi desteğine ilişkin, sağlık otoritelerinin rehberleri incelendiğinde herhangi bir öneriye rastlanmamıştır. Bununla birlikte, FKÜ’lü bebeklerde UZÇDYA içeren mamaların tercih edilmesinin ve tüm FKÜ'lü hastalarda EYA eklenmiş aminoasit karışımlarının kullanımının yararlı olabileceğini, ayrıca FKÜ'lü hastaların en az 6 ay boyunca diyetine eklenecek yaklaşık $500 \mathrm{mg} / g u ̈ n$ (\%18 EPA, \%12 DHA) balık yağının olumlu sonuçlar sağlayabileceğini gösteren çalışmalar mevcuttur. Ancak, bu çalışmalar oldukça sınırlıdır ve FKÜ’lü hastalarda farklı yaş grupları için yararlı işlevsel sonuçlar sağlayacak ve uzun dönem kullanımında olası yan etkileri en az olan doza karar verebilmek için kanıt sağlayacak ileri çalışmalara gereksinme vardır.

Çıkar çatışması - Conflict of interest: Yazarlar çıkar çatışması olmadığını beyan ederler. - The authors declare that they have no conflict of interest.

\section{KAYNAKLAR}

1. Burr G, Burr M. A new deficiency disease produced by the rigid exclusion of fat from the diet. J Biol Chem 1929;82:345-67.

2. Bang HO, Dyerberg J. Plasma lipids and lipoproteins in Greenlandic west coast Eskimos. Acta Med Scand 1972;192:85-94.

3. Dyerberg J, Bang HO, Hjorne N. Fatty acid composition of the plasma lipids in Greenland Eskimos. Am J Clin Nutr 1975;28:958-66.

4. Koletzko B, Sauerwald T, Demmelmair H, Herzog M, von Schenck U, Böhles H, et al. Dietary long chain polyunsaturated fatty acid supplementation in infants with phenylketonuria: A randomized controlled trial. J Inherit Metab Dis 2007;30:326-32.

5. Lohner S, Fekete K, Decsi T. Lower n-3 long-chain polyunsaturated fatty acid values in patients with phenylketonuria: A systematic review and metaanalysis. Nutr Res 2013;33:513-20.

6. Campoy C, Escolano-Margarit MV, Anjos T, Szajewska H, Uauy R. Omega 3 fatty acids on child growth, visual acuity and neurodevelopment. Br J Nutr 2012;107:85106.

7. Koletzko B, Beblo S, Demmelmair H, Hanebutt FL. Omega-3 LC-PUFA supply and neurological outcomes in children with phenylketonuria (PKU). J Pediatr Gastroenterol Nutr 2009;48:2-7.

8. Bone A, Kuehl AK, Angelino AF. A neuropsychiatric perspective of phenylketonuria I: Overview of phenylketonuria and its neuropsychiatric sequelae. Psychosomatics 2012;53:517-23.

9. Konukoğlu D. Omega-3 ve omega-6 yağ asitlerinin özellikleri, etkileri ve kardiyovasküler hastalıklar ile ilişkileri. Türk Aile Hek Derg 2008;12:121-9. 
10. European Food Safety Authority (EFSA). Scientific opinion on dietary reference values for fats, including saturated fatty acids, polyunsaturated fatty acids, monounsaturated fatty acids, trans fatty acids, and cholesterol. EFSA Journal 2010;8:1461.

11. Gezer C, Samur G. Omega-3 yağ asitlerinin bilişsel gelişimdeki rolü. Bes Diy Derg 2012;40:43-9.

12. Abu-Ouf NM, Jan MM. The influence of fish oil on neurological development and function. Can J Neurol Sci 2014;41:13-8.

13. Brenna JT, Varamini B, Jensen RG, Diersen-Schade DA, Boettcher JA, Arterburn LM. Docosahexaenoic and arachidonic acid concentrations in human breast milk worldwide. Am J Clin Nutr Neurosci 2007;85:1457-64.

14. Yuhas R, Pramuk K, Lien EL. Human milk fatty acid composition from nine countries varies most in DHA. Lipids 2006;41:851-8.

15. Food and Agriculture Organization \& World Health Organization. Fats and Oils in Human Nutrition. Vol Paper no. 57. Rome: FAO; 1994.

16. World Health Organization. Diet, Nutrition and the Prevention of Chronic Diseases. Consultation JWFE (eds). Geneva: WHO;2003.

17. Kris-Etherton PM, Innis S. Position of the American Dietetic Association and Dietitians of Canada: Dietary fatty acids. J Am Diet Assoc 2007;107:1599-611.

18. European Food Safety Authority (EFSA). Scientific opinion on nutrient requirements and dietary intakes of infants and young children in the European Union. EFSA Journal 2013;11:3408.

19. Hacettepe Üniversitesi Sağlık Bilimleri Fakültesi Beslenme ve Diyetetik Bölümü. Türkiye’ye Özgü Besin ve Beslenme Rehberi. Yenilenmiş 1. Baskı. Ankara: Hacettepe Üniversitesi Sağlık Bilimleri Fakültesi Beslenme ve Diyetetik Bölümü; 2015.

20. Koletzko B, Lien E, Agostoni C, Böhles H, Campoy C, Cetin I, et al. The roles of longchain polyunsaturated fatty acids in pregnancy, lactation and infancy: Review of current knowledge and consensus recommendations. J Perinat Med 2008;36:5-14.

21. Agostoni C, Braegger C, Decsi T, Kolacek S, Mihatsch W, Moreno LA, et al. Supplementation of n-3 LCPUFA to the diet of children older than 2 years: A commentary by the espghan committee on nutrition. J Pediatr Gastroenterol Nurt 2011;53:2-10.

22. European Food Safety Authority (EFSA). Scientific opinion on the tolerable upper intake level of eicosapentaenoic acid (EPA), docosahexaenoic acid (DHA) and docosapentaenoic acid (DPA). EFSA Journal 2012;10:2815.

23. Calder PC. Mechanisms of action of (n-3) fatty acids. J Nutr 2012;142:592-9.
24. Infante JP, Huszagh VA. Impaired arachidonic (20:4n6) and docosahexaenoic (22:6n-3) acid synthesis by phenylalanine metabolites as etiological factors in the neuropathology of phenylketonuria. Mol Genet Metab 2001;72:185-98.

25. Cornejo V, Concha M, Cabello JF, Raimann E. Lipids composition diet in phenylketonuric children with early diagnosis. Arch Latinoam Nutr 2005;55:332-5.

26. LaVoie SM, Harding CO, Gillingham MB. Normal fatty acid concentrations in young children with phenylketonuria (PKU). Top Clin Nutr 2009;24:333-40.

27. Giovannini M, Verduci E, Radaelli G, Lammardo A, Minghetti D, Cagnoli G, et al. Long-chain polyunsaturated fatty acids profile in plasma phospholipids of hyperphenylalaninemic children on unrestricted diet. Prostaglandins Leukot Essent Fatty Acids 2011;84:39-42.

28. Gramer G, Haege G, Langhans CD, Schuhmann V, Burgard P, Hoffmann GF. Long-chain polyunsaturated fatty acid status in children, adolescents and adults with phenylketonuria. Prostaglandins Leukot Essent Fatty Acids 2016;109:52-7.

29. Russo GL. Dietary n-6 and n-3 polyunsaturated fatty acids: From biochemistry to clinical implications in cardiovascular prevention. Biochem Pharmacol 2009;77:937-46.

30. Riediger ND, Othman RA, Suh M, Moghadasian MH. A systemic review of the roles of n-3 fatty acids in health and disease. J Am Diet Assoc 2009;109:668-79.

31. Agostoni C, Marangoni F, Riva E, Giovannini M, Galli C. Plasma arachidonic acid and serum thromboxane $B_{2}$ concentrations in phenylketonuric children negatively correlate with dietary compliance. Prostaglandins Leukot Essent Fatty Acids 1997;56:219-22.

32. Mütze U, Beblo S, Kortz L, Matthies C, Koletzko B, Bruegel M, et al. Metabolomics of dietary fatty acid restriction in patients with phenylketonuria. PLoS One 2012;7(8):e43021.

33. Htun P, Nee J, Ploeckinger U, Eder K, Geisler T, Gawaz M, et al. Fish-free diet in patients with phenylketonuria is not associated with early atherosclerotic changes and enhanced platelet activation. PLoS One 2015;10(8):e0135930.

34. MacDonald A, Rocha JC, van Rijn M, Feillet F. Nutrition in phenylketonuria. Mol Genet Metab 2011;104:10-8.

35. Brumm VL, Grant ML. The role of intelligence in phenylketonuria: A review of research and management. Mol Genet Metab 2010;99:18-21.

36. VanZutphen K, Packman W, Sporri L, Needham M, Morgan C, Weisiger $\mathrm{K}$, et al. Executive functioning in children and adolescents with phenylketonuria. Clin Genet 2007;72:13-8.

37. Blau N, van Spronsen FJ, Levy HL. Phenylketonuria. 
Lancet 2010;376:1417-27.

38. Beblo S, Reinhardt H, Demmelmair H, Muntau AC, Koletzko B. Effect of fish oil supplementation on fatty acid status, coordination, and fine motor skills in children with phenylketonuria. J Pediatr 2007;150:47984.

39. Koletzko B, Beblo S, Demmelmair H, Müller-Felber W, Hanebutt FL. Does dietary DHA improve neural function in children? Observations in phenylketonuria. Prostaglandins Leukot Essent Fatty Acids 2009;81:15964.

40. Agostoni C, Scaglioni S, Bonvissuto M, Bruzzese MG, Giovanini M, Riva E. Biochemical effects of supplemented long-chain polyunsaturated fatty acids in hyperphenylalaninemia. Prostaglandins Leukot Essent Fatty Acids 2001;64:111-5.

41. Agostoni C, Verduci E, Massetto N, Fiori L, Radaelli G, Riva
E, et al. Long term effects of long chain polyunsaturated fats in hyperphenylalaninemic children. Arch Dis Child 2003;88:582-3.

42. Koçum Y, Köksal G, Özel HG, Coşkun T. Fenilketonürili hastalara omega-3yağsitleriverilmesinin antropometrik ölçümler, biyokimyasal parametreler ve bilişsel gelişimdeki etkisinin incelenmesi. VIII Uluslararası Katılımlı Beslenme ve Metabolik Hastalıklar Kongre Kitabı 2005;G2S5:21.

43. Jans JJ, de Sain-van der Velden MG, van Hasselt PM, van den Hurk DT, Vaz FM, Visser G, et al. Supplementation with a powdered blend of PUFAs normalizes DHA and AA levels in patients with PKU. Mol Genet Metab 2013;109:121-4.

44. Acosta PB, Yannicelli S. The Ross Metabolic Formula System Nutrition Support Protocols. 4th edition. Columbus, Ohio: Abbott Laboratories;2001. 